\title{
Development of two novel nontoxic mutants of Escherichia coli heat-labile enterotoxin
}

\author{
Eun Jeong Park, ${ }^{1}$ Ji Hoon Chang, ${ }^{1}$ \\ Jang Seong Kim, ${ }^{1}$ Soo II Chung ${ }^{1}$ and \\ Jung Sun Yum ${ }^{1,2}$ \\ 1 Mogam Biotechnology Research Institute, 341 Pojungri, Koosungmyun, Yonginsi, \\ Kyonggido 449-910, Korea \\ 2 Corresponding author: Tel, 82-331-262-3851; Fax, 82-331-262-6622; E-mail, \\ jsyum@kgcc.co.kr \\ Accepted 17 May 1999
}

Abbreviations: ETEC, enterotoxigenic Escherichia coli; LT, Escherichia coli heat-labile enterotoxin; $C T$, cholera toxin; $G_{M 1}$, monosialoganglioside; ELISA, enzyme-linked immunosorbent assay

\begin{abstract}
Escherichia coli heat-labile enterotoxin (LT) is composed of catalytic A and non-catalytic homo-pentameric B subunits and causes diarrheal disease in human and animals. In order to produce a nontoxic LT for vaccine and adjuvant development, two novel derivatives of LT were constructed by a site-directed mutagenesis of A subunit; $\operatorname{Ser}^{63}$ to Tyr ${ }^{63}$ in LTS63Y and Glu ${ }^{110}$, Glu $^{112}$ were deleted in $\mathrm{LT}_{\Delta \mathbf{1 1 0}} \mathbf{1 1 2}$. The purified mutant LTs (mLTs) showed a similar molecular structural complex as $A B_{5}$ to that of wild LT. In contrast to wild-type LT, mLTs failed to induce either elongation activity, ADP-ribosyltransferase activity, cAMP synthesis in $\mathrm{CHO}$ cells or fluid accumulation in mouse small intestine in vivo. Mice immunized with mLTs either intragastrically or intranasally elicited high titers of LT-specific serum and mucosal antibodies comparable to those induced by wild-type LT. These results indicate that substitution of Ser ${ }^{63}$ to $\mathrm{Tyr}^{63}$ or deletion of Glu ${ }^{110}$ and $\mathrm{Glu}^{112}$ eliminate the toxicity of LT without a change of $\mathrm{AB}_{5}$ conformation, and both mutants are immunogenic to LT itself. Therefore, both $\mathrm{mLTs}$ may be used to develop novel anti-diarrheal vaccines against enterotoxigenic $E$. coli.
\end{abstract}

Keywords: mutant LT (mLT), ADP-ribosyltransferase activity, cAMP, immunogenicity, secretory $\lg \mathrm{A}(\operatorname{slg} \mathrm{A})$

\section{Introduction}

Enterotoxigenic Escherichia coli (ETEC) strain causes diarrheal disease in human and animals due to production of toxins such as heat-labile enterotoxin (LT) (Spangler, 1992). LT is a multimeric protein composed of two functionally distinct domains; the enzymatically active $A$ subunit (LTA; Mr, 30,000 daltons) with ADP-ribosylating activity, and the pentameric B subunits (LTB; Mr, 11,600 daltons) that contain $\mathrm{G}_{\mathrm{M} 1}$ (monosialoganglioside) receptorbinding site (Bäckström et al., 1997). Upon thiol reduction, the $A$ subunit dissociates into two polypeptide chains, A1 (Mr, 23,000 daltons) and $\mathrm{A} 2$ (Mr, 6,000 daltons) (Tsuji et al., 1985; Grant et al., 1994). The A1 subunit, in particular, intoxicates eucaryotic cells by catalyzing ADP-ribosylation of the protein Gs, a GTP-binding protein that regulates the levels of the second messenger cAMP (Guerrant et al., 1974; Field et al., 1989). The resulting increase in cAMP levels causes secretion of water and electrolytes into the small intestine through interaction with two cAMPsensitive ion transport mechanisms including (i) $\mathrm{NaCl}$ co-transport across the brush border of villous epithelial cells and (ii) electrogenic $\mathrm{Na}^{+}$-dependent $\mathrm{Cl}^{-}$secretion by crypt cells (Guidry et al., 1997).

Both the cholera toxin (CT) from Vibrio cholerae and heat-labile enterotoxin (LT) from ETEC belong to the most potent mucosal adjuvants and immunogens known to date by oral and other mucosal routes, where most of antigens are unable to induce immune responses (Jackson et al., 1993; Takahashi et al., 1996). However, their toxi-cities have precluded usages in human (Douce et al., 1995). One approach to overcome the problem of toxicity is the generation of genetically detoxified derivatives of LT (Lobet et al., 1991; Dickinson and Clements, 1995) and CT (Fontana et al., 1995; Yamamoto et al., 1997b) by a site-directed mutagenesis of amino acids which are located on the $\beta$ strand that constitutes the 'floor' of NAD-binding cavity.

The most important factor for immunogenicity is shown to be the ability to bind to the receptor on eucaryotic cell (Nashar et al., 1996). In fact, a nonbinding mutant of the $B$ subunit of LT was found to be nonimmunogenic (Guidry et al., 1997). Also, another group found that the ADPribosylating activity was unnecessary for immunogenicity because nontoxic derivatives of LT obtained by a sitedirected mutagenesis of the $A$ subunit retained the immunological properties of the wild-type LT (Pizza et al., 1994).

The attempt to define the role of ADP-ribosylating activity in LT adjuvanticity has generated conflicting results. For example, it was reported that a nontoxic derivative of LT (LTE112K) when co-administered with keyhole limpet hemocyanin (KLH) by an oral route in mice, lacked the adjuvant properties, thus suggesting that the adjuvanticity of $L T$ is linked to its ADP-ribosylating activity (Lycke et al., 1992). However, more recently, the adjuvant 
activity of the LTE112K was found to be identical to that of the LT holotoxin when delivered with influenza virus surface antigen by an intranasal route (Verweij et al., 1998). On the other hand, other investigators showed that another LT derivative, LTK63, lacking enzymatic activity and toxicity was still able to elicit antibody responses against the co-administered antigen in mice immunized orally, intranasally, or intravaginally (Di Tommaso et al., 1996; Giuliani et al., 1998; Marchetti et al., 1998).

In an effort to develop anti-diarrheal vaccine or mucosal adjuvant, we constructed nontoxic $\mathrm{mLTs}$, LTS63Y and LT $\Delta 110 / 112$ by site-directed mutagenesis, each of which contains a single amino acid substitution and deletion of two amino acids, respectively, in the ADP-ribosyltransferase active center. We have demonstrated that in contrast to wild-type LT, both the LTS63Y and LT $\Delta 110$ / 112 did not induce any toxic activities. Both the mutants elicited high and comparable levels of anti-LT antibodies when delivered either intragastrically or intranasally, inducing systemic and local responses in serum and fecal extracts. Thus, they might be useful for the development of a novel diarrheal vaccine in human and animals.

\section{Materials and Methods}

\section{Plasmid construction and mutagenesis}

A 1.5-kb BamHI DNA fragment including LT gene from porcine-origin, entero-toxigenic $E$. coli K88ac strain was cloned into pBluescript $\mathrm{KS}^{-}$vector (pBlueKS $/ \mathrm{rLT}^{-}$). Singlestranded DNA was prepared from the culture supernatant of $E$. coli CJ 236 transformed with pBlueKS $/ / \mathrm{rLT}$ and then subjected to a site-directed mutagenesis using Mutan $\mathrm{K}$ (Takara Biomedicals, Kyoto, Japan). The sequences of oligonucleotides used for the substitution (S63Y) and deletion $(\Delta 110 / 112)$ were 5'-ATATGATGACGGATATGTTTC CACTTACCTTAGTTTGAGAAGTGCTCACTTG-3' and 5'-AG GCGTATACAGCCCTCACCCATATCAGGTTTCTGCGTTAGGT GGAATACCAT-3', respectively. Serine at position 63 was substituted for tyrosine at LTS63Y and glutamic acids in position 110 and 112 were deleted in LT $\Delta 110 / 112$. These residues are in proposed ADP-ribosyltransferase active center of $L T$ and their substitutions or deletions have been shown to inactivate ADP-ribosyltransferase activity and enterotoxicity. We confirmed the changes of DNA sequences using Sequenase Version 2.0 sequencing kit (Amersham Life Science, USA).

\section{Purification of recombinant $\mathrm{mLTs}$}

pBluescript KS vectors containing mutant LT genes were transformed into E. coli Top10F' (Invitrogen, USA). The mutant LTs were purified from cultures grown overnight. The cells were harvested by centrifugation, resuspended in TEAN buffer $(0.2 \mathrm{M} \mathrm{NaCl}, 50 \mathrm{mM}$ Tris, $1 \mathrm{mM}$ EDTA and $3 \mathrm{mM} \mathrm{NaN}_{3}$ [pH 7.5]), and lysed with microfluidizer (Microfluidics Corporation, USA). The lysates were clarified by centrifugation and then filtered using 0.45 $\mu \mathrm{m}$ membrane (Micro Filtration Systems, Japan) prior to chromatography on immobilized D-galactose column (Pierce, USA) (Uesaka et al., 1994). The mLTs were eluted with $0.3 \mathrm{M}$ galactose in TEAN buffer. Holotoxin $\left(A B_{5}\right)$ fraction was separated from the free B-subunit pentamers by size exclusion chromatography using FPLC Superdex 200 column (Pharmacia, Sweden).

\section{Cell elongation assay}

The ability of $\mathrm{mLTs}$ to induce morphological changes in cultured Chinese hamster ovary-K1 (CHO-K1) (ATCC, USA) cells was tested as previously described (Guerrant et al., 1974). CHO-K1 cells were incubated for $24 \mathrm{~h}$ as monolayer cultures in minimal essential medium alpha $(\mathrm{MEM}-\alpha)$ (GibcoBRL, USA) supplemented with $10 \%$ fetal bovine serum (FBS) in a humidified, $5 \% \mathrm{CO}_{2}$ atmosphere at $37^{\circ} \mathrm{C}$. The cells were washed once with Hanks's balanced salt solution (HBSS) and then removed from the flask by incubation of the cells with $0.1 \%$ trypsin for $5 \mathrm{~min}$. After centrifugation, they were washed once, and then resuspended in the growth medium. To each well of a 48-well tissue culture plate, the same numbers of $\mathrm{CHO}-\mathrm{K} 1$ cells $\left(10^{4}\right.$ in a $200-\mu$ l volume per well) were added. The cells were allowed to adhere for $4 \mathrm{~h}$ prior to the addition of the toxin dilutions and then incubated for $24 \mathrm{~h}$ in a humidified, $5 \% \mathrm{CO}_{2}$ atmosphere at $37^{\circ} \mathrm{C}$. Cells were then washed with phosphate-buffered saline (PBS), fixed with methanol, and stained with $0.04 \%$ Trypan Blue Stain (GibcoBRL). After staining, the cells were washed, air dried, and analyzed for morphological changes by light microscopy.

\section{ADP-ribosyltransferase activity test}

For the preparation of crude membranes, $\mathrm{CHO}-\mathrm{K} 1$ cells were maintained in monolayer culture by serial passages in MEM- $\alpha$ medium supplemented with $10 \%$ FBS (Locht et al., 1987). The cells were detached from the flask, resuspended in PBS $(\mathrm{pH} \mathrm{7.2)}$ and then sedimented by centrifugation at $1,000 \mathrm{~g}$ for $10 \mathrm{~min}$. The cells were resus-pended in ice-cold $25 \mathrm{mM}$ Tris- $\mathrm{HCl}(\mathrm{pH}$ 7.5) containing $5 \mathrm{mM} \mathrm{MgCl}_{2}$, allowed to equilibrate for $15 \mathrm{~min}$ on ice and then homogenized. The homogenate was centrifuged at $600 \mathrm{~g}$ for $10 \mathrm{~min}$ at $4^{\circ} \mathrm{C}$ to remove nuclei and intact cells. The postnuclear supernatant fractions were centrifuged at $18,000 \mathrm{~g}$ for $7 \mathrm{~min}$ to yield a microsomal or membrane pellet. The pelleted material was suspended in $50 \mathrm{mM}$ Tris- $\mathrm{HCl}(\mathrm{pH} \mathrm{8.0)}$ and centrifuged at $18,000 \mathrm{~g}$ for $7 \mathrm{~min}$. The final washed membrane pellet was resuspended in $50 \mathrm{mM}$ Tris- $\mathrm{HCl}$ (pH 8.0) at a concentration of $1 \mathrm{mg}$ of protein per $\mathrm{ml}$ and stored at $-70^{\circ} \mathrm{C}$ until used. 
ADP-ribosyltransferase activity was determined as the ability to catalyze the transfer of labeled ADP-ribose from [adenylate- ${ }^{32} \mathrm{P}$ ]NAD to the $41 \mathrm{kDa}$ G protein in CHO-K1 membranes (Locht et al., 1987). Reaction mixtures $(100 \mu \mathrm{l})$ containing $32 \mu \mathrm{M}$ [adenylate- $\left.{ }^{32} \mathrm{P}\right] \mathrm{NAD}$ $(2 \mu \mathrm{Ci})$ (NEN, USA), $10 \mathrm{mM}$ thymidine, $100 \mu \mathrm{M}$ ATP, 20 mM DTT, $100 \mu \mathrm{M}$ GTP, $50 \mu \mathrm{g}$ of CHO-K1 membrane proteins, $50 \mathrm{mM}$ Tris- $\mathrm{HCl}(\mathrm{pH} \mathrm{8.0)}$ and $10 \mu \mathrm{g}$ of wildtype $\mathrm{LT}$ or $\mathrm{mLT}$ were incubated at $37^{\circ} \mathrm{C}$ for $30 \mathrm{~min}$. The reactions were terminated by the addition of $1 \mathrm{ml}$ of icecold $50 \mathrm{mM}$ Tris- $\mathrm{HCl}(\mathrm{pH} \mathrm{8.0)}$, and the membranes were sedimented by centrifugation at $15,000 \mathrm{~g}$ for $7 \mathrm{~min}$ at $4^{\circ} \mathrm{C}$. The membrane pellet was resuspended in ice-cold Tris- $\mathrm{HCl}(\mathrm{pH} 8.0)$ and sedimented once more by centrifugation before solubilization in $50 \mu \mathrm{l}$ of electrophoresis sample buffer containing $5 \% \beta$-mercaptoethanol. The samples were heated to $95^{\circ} \mathrm{C}$ for $5 \mathrm{~min}$ and then analyzed by SDS-PAGE and autoradiography.

\section{Measurement of intracellular cAMP accumulation}

$\mathrm{CHO}$ cells (ATCC) were maintained in MEM- $\alpha$ medium supplemented with $10 \%$ FBS in 24 -well plate at a concentration of $5 \times 10^{4}$ cells per well, grown to near confluency, and incubated in MEM- $\alpha$ containing $1 \%$ FBS and $1 \mathrm{mM}$ IBMX for $30 \mathrm{~min}$ prior to addition of toxins (Grant et al., 1994). Either CT, CTB, trypsinactivated wild-type LT, LTS63Y, or LT $\Delta 110 / 112$ was added to each well and incubated for $18 \mathrm{~h}$. The cells were then washed three times with PBS. Intracellular cAMP was extracted by adding $200 \mu \mathrm{l}$ of $50 \mathrm{mM} \mathrm{HCl}$ to each well and incubating the plates in $-70^{\circ} \mathrm{C}$ deep freezer for 20 min. cAMP was measured with a Biotrak cAMP enzyme-immunoassay (EIA) system (Amersham Life Science) as described by manufacturer's instructions.

\section{Assessment of toxicity using mouse ileal loops}

The enterotoxicity of $\mathrm{mLTs}$ was examined using a mouse ileal loop test (Yamamoto et al., 1997b). Groups of mice were anesthetized, and $100 \mu$ of PBS containing different doses of toxins were injected into ileal loops (LT, $100 \mathrm{ng}$ or $1 \mu \mathrm{g}$ per mouse; $\mathrm{mLT}, 10 \mu \mathrm{g}$ or $100 \mu \mathrm{g}$ per mouse). The mice were killed $18 \mathrm{~h}$ after the injection, and the ratio of fluid to length was determined and defined as positive when the ratio was more than $40 \mu \mathrm{l} / \mathrm{cm}$.

\section{Mice and their immunization}

Female Balb/c mice aged 6 weeks old were purchased from Charles River (Japan). For intragastric immunization, antigens were resuspended in PBS $(\mathrm{pH} 7.2)$ buffer containing $0.35 \mathrm{M} \mathrm{NaHCO}_{3}$ and delivered in a volume of $0.5 \mathrm{ml}$ per mouse. Mice were immunized intragastrically with $25 \mu \mathrm{g}$ of each toxin on days $0,7,14$, and 21 (Takahashi et al., 1996). For intranasal immunization, mice were delivered with a $20-\mu$ l aliquot (10 $\mu \mathrm{l}$ per nostril) containing $2 \mu \mathrm{g}$ of each toxin on days 0 , 7, and 14 (Yamamoto et al., 1997a).

\section{$\mathrm{G}_{\mathrm{M1} 1}$-ELISA}

LT-specific antibodies were measured with a $G_{M 1}$ capture enzyme-linked immunosorbent assay ( $G_{M 1}$-ELISA) (Spiegel, 1990; Douce et al., 1997). Plates were coated with 150 ng of $\mathrm{G}_{\mathrm{M} 1}$ (Sigma, USA) suspended in PBS per well of 96-well EIA/RIA plate (Costar, USA) and then incubated at $37^{\circ} \mathrm{C}$ for $1 \mathrm{~h}$. Plates were washed three times with PBS containing $0.05 \%$ Tween 20 (PBST) and blocked for $1 \mathrm{~h}$ at $37^{\circ} \mathrm{C}$ with $2.5 \%$ skim milk (Difco, USA) in PBST. After washing with PBST three times, $100 \mathrm{ng}$ of wild-type LT was added into wells and plates were incubated for $1 \mathrm{~h}$ at $37^{\circ} \mathrm{C}$ and washed three times with PBST. Sera or fecal samples obtained (Jackson et al., 1993; Yamamoto et al., 1997a) from each mouse were tested by using two-fold serial dilutions and incubated for $2 \mathrm{~h}$ at $37^{\circ} \mathrm{C}$. After washing with PBST six times, the plates were incubated for $1 \mathrm{~h}$ at $37^{\circ} \mathrm{C}$ with an appropriate anti-mouse immunoglobulin $\mathrm{G}(\lg G)$ or $\lg A$ antibody (KPL, USA) conjugated with horseradish peroxidase (HRP) and washed as described above. Bound antibodies were visualized by adding 3,3',5,5'tetramethylbenzidine (TMB) substrate. Absorbancies were read at $450 \mathrm{~nm}$ and ELISA titers were arbitrarily determined as the dilution of serum which gave an optical density value above the level measured in preimmune samples.

\section{Results and Discussion}

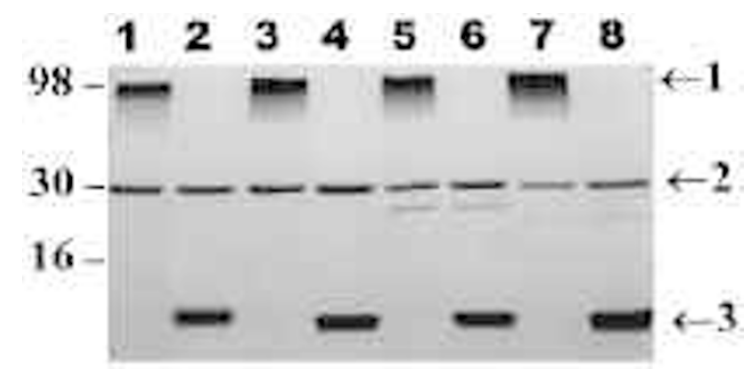

Figure 1. Analytical SDS-PAGE of wild-type LT and $\mathrm{mLTS}$. E. coli lysates containing LT, LTS63Y, and LT $\Delta 110 / 112$ were chromatographed on an immobilized D-galactose column and then eluted with $0.3 \mathrm{M}$ galactose in TEAN buffer as described in 'Materials and Methods'. Lane 1 and 2, LT purchased from Sigma; 3 and 4, recombinant LT; 5 and 6, LTS63Y; 7 and 8, LT $\Delta 110 / 112$. Each well contained $10 \mu \mathrm{g}$ and samples in lanes $2,4,6$, and 8 were heated to $95^{\circ} \mathrm{C}$ for $5 \mathrm{~min}$ in the presence of $\beta$ mercaptoethanol. Arrow 1, LT holotoxins and LTB pentamers; arrow 2, LTA subunits; arrow 3, LTB monomers. 


\section{Expression and purification of $\mathrm{mLTs}$}

Ser $^{63}$ was substituted to Tyr ${ }^{63}$ in LTS63Y and Glu ${ }^{110}$ and Glu ${ }^{112}$ were deleted in LT $\Delta 110 / 112$. These residues located in or near the NAD-binding site of LT have been shown to be essential for the ADP-ribosyltransferase activity of LT (Domenighini et al., 1994). We expressed the mLTs, LTS63Y and LT $\Delta 110 / 112$, in the plasmid vector (pBlueKS $/$ rLTS63Y or pBlueKS $/$ rLT $\Delta 110 / 112$ ), containing the coding (1.2 kb) and regulatory (160 bp of 5'- and 197 bp of 3'-noncoding genes) regions. The recombinant proteins were purified by immobilized Dgalactose column chromatography. The homogeneity of LTS63Y and LT $\Delta 110 / 112$ was confirmed by SDS-PAGE, as shown in Figure 1. When the purified $\mathrm{mLTs}$ were

Table 1. Comparison of biologic and enzymatic activity of wild-type LT, LTS63Y, and LT $\Delta 110 / 112$.

\begin{tabular}{lll}
\hline Toxin assessed & Cell elongation & lleal loop test \\
\hline PBS & $10 \%<$ & Negative \\
Wild-type LT & $90 \%>$ at $100 \mathrm{ng}$ & Positive at $100 \mathrm{ng}$ \\
S63Y & $10 \%<$ at $10 \mu \mathrm{g}$ & Negative at $100 \mu \mathrm{g}$ \\
$\Delta 110 / 112$ & $10 \%<$ at $10 \mu \mathrm{g}$ & Negative at $100 \mu \mathrm{g}$ \\
\hline
\end{tabular}

a $10^{4}$ cells of CHO-K1 cells were cultured with $100 \mathrm{ng}$ of wild-type LT or $10 \mu \mathrm{g}$ of each $\mathrm{mLT}$ for $24 \mathrm{~h}$ and a positive toxin effect on the CHO-K1 cells was defined as elongation of $>20 \%$ of the cells according to published criteria (Yamamoto et al., 1997b).

${ }^{b}$ The enterotoxicity of $\mathrm{mLTs}$ was examined using an ileal loop test, where mice were anesthetized, and $100 \mu$ of PBS containing $100 \mathrm{ng}$ of wt LT or $100 \mu \mathrm{g}$ of each mLT were injected into an ileal loop. Loops were examined $18 \mathrm{~h}$ later and the ratio of fluid to length was defined as positive when the ratio was $>40 \mu \mathrm{l} / \mathrm{cm}$ (Yamamoto et al., 1997b). analyzed without boiling, two protein bands were appeared; one band with the size of $70-100 \mathrm{kDa}$ corresponding to the holotoxin and LTB pentamers, and the other band with the size of about $30 \mathrm{kDa}$ corresponding to the LTA subunit. When the purified $\mathrm{mLTs}$ were boiled for $5 \mathrm{~min}$, the holotoxins were dissociated into two bands of about 30 and $11 \mathrm{kDa}$, corresponding to the $A$ and $B$ subunits of $L T$, respectively. Since the mobilities of $\mathrm{mLTs}$ were identical to those of the wild-type LT (Figure 1), the molecular weights of the $\mathrm{mLT}$ subunits were presumed to be identical to those of wild-type LT. These results suggested that the innate structure of the $A$ subunit associated with pentameric $B$ subunits of LT was not affected by substitution of tyrosine for $\mathrm{Ser}^{63}$ or deletion of Glu $^{110}$ and Glu $^{112}$ residues on NAD-binding pocket. Moreover, it was demonstrated that the binding ability of the $B$ subunit of $m L T s$ to $G_{M 1}$ ganglioside was similar to that of the normal $B$ subunit using a $G_{M 1}$-ELISA, and $\mathrm{mLTs}$ were reacted with anti-LT antibody in Western blot analysis (data not shown). These results imply that $\mathrm{mLT}$ s retain the $\mathrm{AB}_{5}$ conformation similar to wild-type LT.

\section{Assays for biologic, enzymatic, and toxic activities of $\mathbf{m L T s}$}

Enzymatic and biologic characterizations of $\mathrm{mLTs}$ were carried out to compare their properties with wild-type LT, including cell elongation assay, ADP-ribosyltransferase activity test, cAMP assay and mouse ileal loop test. The morphological changes on the CHO-K1 cells (Grant et al., 1994) were used to detect the toxic activity of $\mathrm{mLTs}$. As little as $100 \mathrm{ng} / \mathrm{ml}$ of LT induced longitudinal growth of approximately $90 \%$ of the $\mathrm{CHO}-\mathrm{K} 1$ cells, a response previously shown to be dependent upon adenylate
A
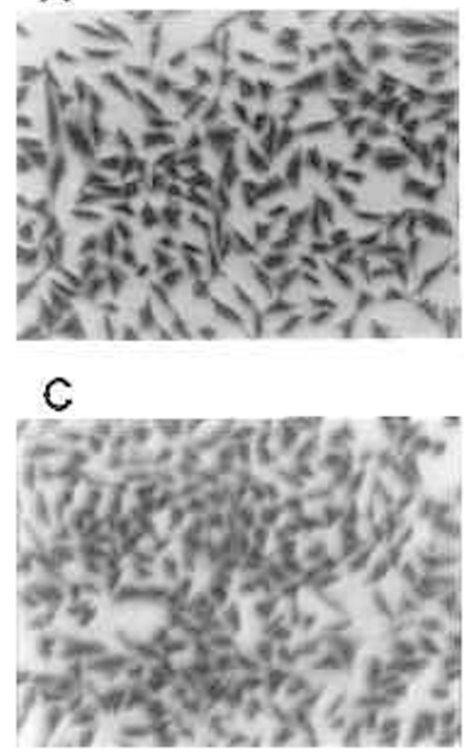

B

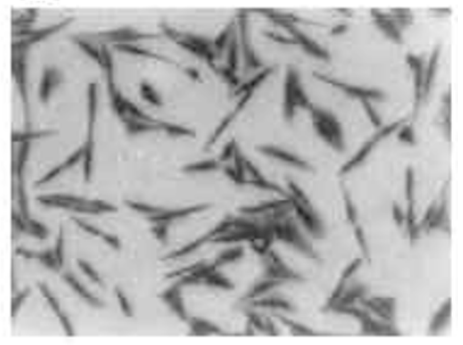

D

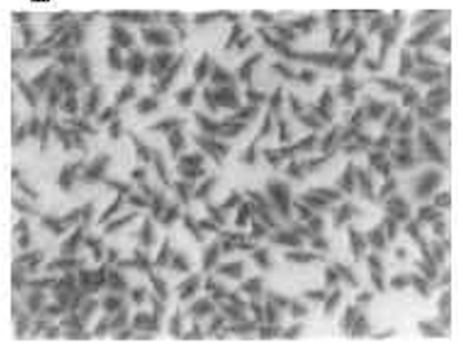

Figure 2. Cell morphologies changed by treatment with wild-type LT or $\mathrm{mLTs}$. A, toxin-untreated; B, wild-type LT-treated $(100 \mathrm{ng} / \mathrm{ml})$; C, LTS63Ytreated $(10 \mu \mathrm{g} / \mathrm{ml}) ; \mathrm{D}, \mathrm{LT} \Delta 110 / 112$-treated $(10 \mu \mathrm{g} / \mathrm{ml})$ CHO-K1 cells $(400$ $X)$. The same numbers of $\mathrm{CHO}-\mathrm{K} 1$ cells $\left(10^{4}\right.$ in a $200-\mu$ l volume per well) were added to each well of a 48-well tissue culture plate. 


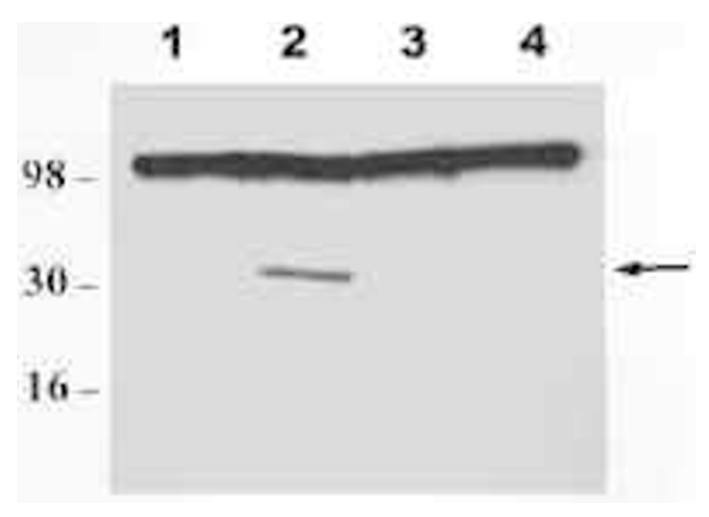

Figure 3. ADP-ribosyltransferase activity of $L T, L T S 63 Y$ and $L T \Delta 110 / 112$. The membrane proteins $(50 \mu \mathrm{g})$ of $\mathrm{CHO}-\mathrm{K} 1$ cells were incubated without toxins (lane 1), with $10 \mu \mathrm{g}$ of wild-type LT (lane 2), $10 \mu \mathrm{g}$ of LTS63Y (lane 3), or $10 \mu \mathrm{g}$ of LT $\Delta 110 / 112$. The conditions are described in 'Materials and Methods'. Reaction mixtures were then analyzed by SDS-PAGE in a $12.5 \%$ gel followed by autoradiography. The arrow denotes the position of the Mr-41,000 band corresponding to the Gs protein.

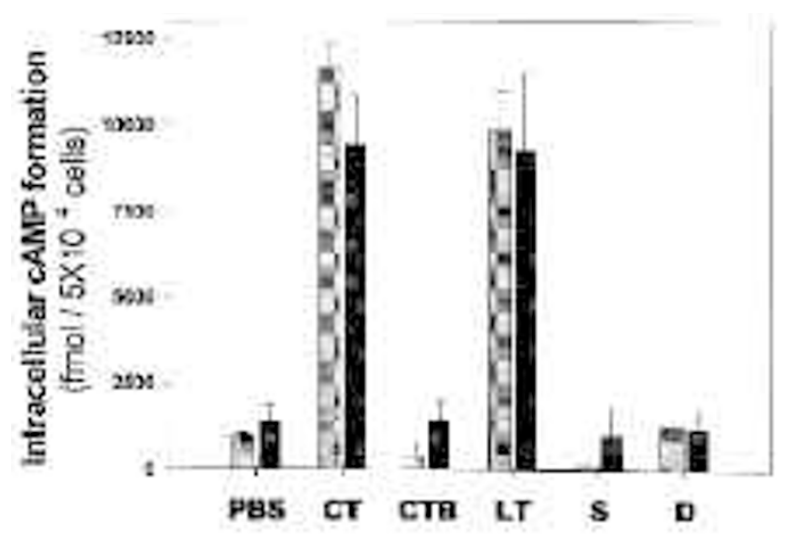

Figure 4. Assay for intracellular cAMP formation. CHO cells were cultured in 24-well plate at a concentration of $5 \times 10^{4}$ cells per well, grown to near confluency, and incubated with each toxin for $18 \mathrm{~h}$. Intracellular CAMP was extracted and measured by an enzyme immunoassay system. CT, cholera toxin; CTB, cholera toxin B subunit; LT, E. coli heat-labile enterotoxin; S, LTS63Y; D, LT $110 / 112$. Gray bars, $500 \mathrm{ng}$ - (CT and LT) or $5 \mu \mathrm{g}$ - (CTB, $S$ and D); black bars, $50 \mathrm{ng}$ - (CT and LT) or $500 \mathrm{ng}$-treated cells (CTB, $S$ and D).

cyclase-induced increases in cAMP (Guerrant et al., 1974). However, the cells treated with $\mathrm{mLT}$ at the level of $10 \mu \mathrm{g} / \mathrm{ml}$ showed no morphological changes of the CHO-K1 cells (Figure 2 and Table 1 ).

In general, the $A 1$ fragment of $L T$ is capable of binding NAD and catalyzing the ADP-ribosylation of Gs, a GTPbinding regulatory protein associated with adenylate cyclase (Spangler, 1992). The consequence is a sharp increase in CAMP production resulting in excessive accumulation of salts and water in the intestinal lumen (Field et al., 1989). A subunits of LT is known to catalyze
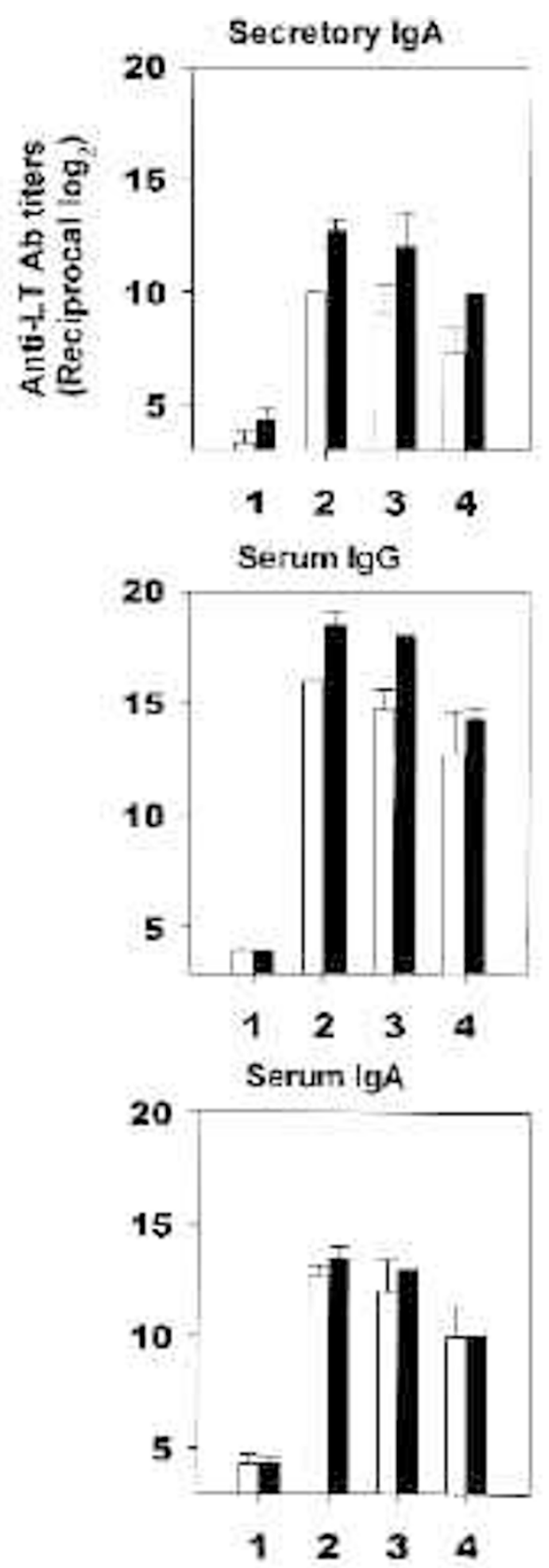

Figure 5. Anti-LT secretory $\lg A$ and serum $\lg G$ and $\lg A$ antibody responses on intragastric (white bars) or intranasal (black bars) immunization. IgA immune responses to $L T$ in fecal extracts and lgG and IgA in sera of mice immunized four- (intragastric) or three- (intranasal) times. 1, PBS; 2, LT; 3, LTS63Y; 4, LT $1110 / 112$. Results are shown as mean titers and error bars indicate the standard deviation from the mean titer.

ADP-ribosylation of the membrane-bound substrate Gproteins. As shown in Figure 3, when the membrane proteins $(50 \mu \mathrm{g})$ from $\mathrm{CHO}-\mathrm{K} 1$ cells were incubated with wild-type LT in the presence of [adenylate- ${ }^{32} \mathrm{P}$ ]NAD, it 
specifically ADP-ribosylated the Mr-41,000 proteins, which correspond to the $\alpha$-subunits of the GTP binding Gs protein (lane 2 in Figure 3). In contrast, no ADPribosylation of this protein was detected in reaction mixtures incubated with the same amounts $(10 \mu \mathrm{g})$ of LTS63Y (lane 3) or LT $\Delta 110 / 112$ (lane 4). This result was identical to that of the negative control treated without toxins (lane 1). Therefore, the substitution of $\operatorname{Ser}^{63}$ to $\mathrm{Tyr}^{63}$ or deletion of Glu ${ }^{110}$ and Glu ${ }^{112}$ in A1 subunit did cause changes in structural integrity of NAD binding crevis that may be important for enzymatic activity of $L T$. To investigate CAMP accumulation induced by $\mathrm{mLT}$, the levels of CAMP were determined in $\mathrm{CHO}$ cells treated with CT, CTB, LT, LTS63Y, or LT $\Delta 110 / 112$. As shown in Figure 4 , the addition of $50 \mathrm{ng} / \mathrm{ml}$ concentration of wildtype CT or LT caused about tenfold higher levels of cAMP production than those of untreated cultures. On the other hand, CAMP formation in cultures treated with CTB, LTS63Y, or LT $\Delta 110 / 112$ was undetectable even at a concentration as high as $5 \mu \mathrm{g} / \mathrm{ml}$. These data showed that the presence of wild-type LTA subunit (accurately LTA1 subunit) is necessary for an increase in the intracellular CAMP concentration and the mutant derivatives, LTS63Y and LT $\Delta 110 / 112$, devoid of enzymatic activity, are unable to form cAMP.

The toxicity of LTS63Y or LT $1110 / 112$ was also assessed in a mouse ileal loop assay. One hundred nanogram of wild-type LT induced significant fluid accumulation in small intestine, however, no fluid accumulation was observed in the loop treated with thousand-fold higher levels $(100 \mu \mathrm{g})$ of $\mathrm{mLTs}$ (Table 1$)$. These data strongly indicate that the $\mathrm{mLTs}$ possess negligible enterotoxicity in vivo.

The derivatization of the wild-type toxin via substitution of a single amino acid or deletion of double amino acids known to be associated with the NAD-binding site on the A subunit resulted in complete loss of enzymatic, biologic, and toxic activities of LT. In particular, two novel mutants LTS63Y and LT $\Delta 110 / 112$ that are shown to be devoid of ADP-ribosyltransferase activity, were unable to induce longitudinal growth of $\mathrm{CHO}-\mathrm{K} 1$ cells, increase intracellular CAMP, and elicit fluid accumulation in mouse-ligated ileal loops. These results have revealed that LTS63Y or LT $\Delta 110 / 112$ is qualitatively, physiologically distinct from wild-type LT.

\section{Immunogenicity of LTS63Y and LT $\Delta 110 / 112$}

The mucosal immunogenicities of LTS63Y and LT $\Delta 110$ / 112 were tested via two immunization routes. Groups of mice were immunized intragastrically four times at weekly intervals with $25 \mu \mathrm{g}$ of LTS63Y or LT $\Delta 110 / 112$ and intranasally three times at the same intervals with $2 \mu \mathrm{g}$ of the antigens. The control groups received PBS alone. The serum and fecal antibody titers to $L T$ were determined using samples prepared on day 7 following the last immunization; the results are shown in Figure 5. The mice immunized with LTS63Y or LT $\Delta 110 / 112$ contained high and comparable levels of anti-LT antibodies in sera and fecal extracts compared with those immunized with wild-type LT. The LTS63Y was slightly more immunogenic than LT $\Delta 110 / 112$ on both intragastric and intranasal administration. On the other hand, titers of anti-LT in the serum or fecal extracts of mice intranasally immunized with wild-type LT or $\mathrm{mLTs}$ were slightly higher than those observed in mice intragastrically administered. Intranasal immunization offers several advantages compared with other immunization routes. Lower doses of proteins are required to induce antibody responses and would decrease the cost for vaccine (Yamamoto et al., 1997a). As shown in Figure 5, when administered intranasally, only $6 \%$ of the quantity of $\mathrm{mLT}$ used in intragastric immunization was required to elicit slightly higher levels of secretory IgA responses and this dose also effectively induced systemic $\lg G$ and $\lg A$ antibody responses. Thus, intranasal immunization using $\mathrm{mLT}$ could be an effective method for vaccination in human and animals.

In summary, this study has shown that both novel mLTs, namely LTS63Y and LT $\Delta 110 / 112$, lacked toxicity but elicited mucosal immunogenicity via two mucosal routes and could be useful for the development of antidiarrheal vaccines. Particularly, both $\mathrm{mLTS}$ appeared to be more immunogenic on intranasal administration. We are currently assessing the mucosal adjuvanticity of these $\mathrm{mLTS}$ to Helicobacter pylori antigens. Further, the protection test using $\mathrm{mLTs}$ as adjuvants against $H$. pylori has been investigated in mice following intranasal immunization

\section{Acknowledgement}

We thank J. H. Lee for excellent technical assistance in animal experiment and J. T. Oh and C. H. Kim for helpful discussions. Thanks are extended to Drs. Y. Yun and D. $\mathrm{H}$. Park for their continued supports. This study was supported by the Korea Green Cross Corporation (KGCC).

\section{References}

Bäckström, M., Shahabi, V., Johansson, S., Teneberg, S., Kjellberg, A., Miller-Podraza, H., Holmgren, J., and Lebens, L. (1997) Structural basis for differential receptor binding of cholera and Escherichia coli heat-labile toxins: influence of heterologous amino acid substitutions in the cholera B-subunit. Mol. Microbiol. 24: 489-497

Dickinson, B. L., and Clements, J. D. (1995) Dissociation of Escherichia coli heat-labile enterotoxin adjuvanticity from ADP-ribosyltransferase activity. Infect. Immun . 63: 16171623

Di Tommaso, A., Saletti, G., Pizza, M., Rappuoli, R., Dougan, G., Abrignani, S., Douce, G., and De Magistris, M. T. (1996) Induction of antigen-specific antibodies in vaginal secretions by using a nontoxic mutant of heat-labile enterotoxin as a mucosal adjuvant. Infect. Immun. 64: 974-979 
Domenighini, M., Magagnoli, C., Pizza, M., and Rappuoli, R. (1994) Common features of the NAD-binding and catalytic site of ADP-ribosyl-ating toxins. Mol. Microbiol. 14: 4150

Douce, G., Turcotte, C., Cropley, I., Roberts, M., Pizza, M., Domenghini, M., Rappulori, M., and Dougan, G. (1995) Mutants of Escherichia coli heat-labile toxin lacking ADP ribosyltransferase activity act as nontoxic, mucosal adjuvants. Proc. Natl. Acad. Sci. USA. 92: $1644-1648$

Douce, G., Fontana, M., Pizza, M., Rappuoli, R., and Dougan, G. (1997) Intranasal immunogenicity and adjuvanticity of site-directed mutant derivatives of cholera toxin. Infect. Immun. 65: 2821-2828

Field, M., Rao, M. C., Chang, E. B. (1989) Intestinal electrolyte transport and diarrheal disease. N. Engl. J. med. 321: 800-806

Fontana, M. R., Manetti, R., Giannelli, V., Magagnoli, C., Marchini, A., Olivieri, R. Domenighini, M., Rappuloli, R., and Pizza, M. (1995) Cons-truction of nontoxic derivatives of cholera toxin and characterization of the immunological response against the A subunit. Infect. Immun. 63: 2356-2360

Giuliani, M.M., Giudice, G. D., Giannelli, V., Dougan, G., Douce, G., Rappuoli, R., and Pizza, M. (1998) Mucosal adjuvanticity and immuno-genicity of LTR72, a novel mutant of Escherichia coli heat-labile entero-oxin with partial knockout of ADPribosyltransferase activity. J. Exp. Med. 187: 1123-1132

Grant, C. C. R., Messer, R. J., and Cieplak, Jr. W. (1994) Role of trypsin-like cleavage at arginine 192 in the enzymatic and cytotonic activities of Escherichia coli heat-labile enterotoxin. Infect.Immun. 62: 4270-4278

Guerrant, R. L., Brunton, L. L., Schnaitman, T. C., Rebhun, L. I., and Gilman, A. G. (1974) Cyclic adenosine monophosphate and alteration of Chinese hamster ovary cell morphology: a rapid, sensitive in vitro assay for the enterotoxins of Vibrio cholerae and Escherichia coli. Infect. Immun. 10: 320-327

Guidry, J. J., Cardenas, L., Cheng E., and Clements, J. D. (1997) Role of receptor binding in toxicity, immunogenicity, and adjuvanticity of Escherichia coli heat-labile enterotoxin. Infect. Immun. 65: 4943-4950

Jackson, R.J., Fujihashi, K., Xu-Amano, J., Kiyono, H., Elson, C. O., and McGhee, J. R. (1993) Optimizing oral vaccines: induction of systemic and mucosal B-cell and antibody responses to tetanus toxoid by use of cholera toxin as an adjuvant. Infect. Immun. 61: $4272-4279$

Lobet, Y., Cluff, C. W., and Cieplak, Jr. W. (1991) Effect of site-directed mutagenic alterations on ADP-ribosyltransferase activity of the A subunit of Escherichia coli heatlabile enterotoxin. Infect. Immun. 59: 2870-2879

Locht, C., Cieplak, W., Marchitto, K. S., Sato, H., and Keith, J. M. (1987) Activities of complete and truncated forms of pertussis toxin subunits $\mathrm{S} 1$ and $\mathrm{S} 2$ synthesized by Escherichia coli. Infect. Immun. 55: 2546-2553

Lycke, N., Tsuji, T., and Holmgren, J. (1992) The adjuvant effect of Vibrio cholerae and Escherichia coli heat-labile enterotoxins is linked to their ADP-ribosyltransferase activity. Eur. J. Immunol. 22: 2277-2281
Marchetti, M., Rossi, M., Giannelli, V., Giuliani, M. M., Pizza, M., Censini, S., Covacci, A., Massari, P., Pagliaccia, C., Manetti, R., Telford, J. L., Douce, G, Dougan, G., Rappuoli, R., and Ghiara, P. (1998) Protection against Helicobacter pylori infection in mice intragastric vaccination with $H$. pylori antigens is achieved using a non-toxic mutant of E. coli heat-labile enterotoxin (LT) as adjuvant. Vaccine. 16: 33-37

Nashar, T. O., Webb, H. M., Eaglestone, S., Williams, N. A., and Hirst, T. R. (1996) Potent immunogenicity of the $B$ subunits of Escherichia coli heat-labile enterotoxin: Receptor binding is essential and induces differ-ential modulation of lymphocyte subsets. Proc. Natt. Acad. Sci. USA. 93: 226-230

Pizza, M., Fontana, M. R., Giuliani, M. M., Domenighini, M., Magagnoli, C., Giannelli, V., Nucci, D., Hol, W., Manetti, R., and Rappuoli, R. (1994) A genetically detoxified derivative of heat-labile Escherichia coli enterotoxin induces neutralizing antibodies against the $A$ subunit. J. Exp. Med. 180: 2147-2153

Spangler, B. D. (1992) Structure and function of cholera toxin and the related Escherichia coli heat-labile enterotoxin. Microbiol. Rev. 56: 622-647

Spiegel, S. (1990) Cautionary note on the use of the B subunit of cholera toxin as a ganglioside $G_{M 1}$ probe: detection of cholera toxin $A$ subunit in $B$ subunit preparations by a sensitive adenylate cyclase assay. J. Cell. Biochem. 42: 143-152

Takahashi, I., Marinaro, M., Kiyono, H., Jackson, R. J., Nakagawa, I., Fujihashi, K., Hamada, S., Clements, J. D., Bost, K. L., and McGhee, J. R. (1996) Mechanism for mucosal immunogenicity and adjuvancy of Escherichia coli labile enterotoxin. J. Infect. Dis. $173: 627-35$

Tsuji, T., Honda, T., Miwatani, T., Wakabayashi, S., and Matsubara, H. (1985) Analysis of receptor-binding site in Escherichia coli enterotoxin. J. Biol. Chem. 260: 8552-8558

Uesaka, Y., Otsuka, Y., Lin, Z., Yamasaki, S., Yamaoka, J., Kurazono, H., and Takeda, Y. (1994) Simple method of purification of Escherichia coli heat-labile enterotoxin and cholera toxin using immobilized galactose. Microb. Pathog. 16: 71-76

Verweij, W. R., de Haan, L., Holtrop, M., Agsteribbe, E., Brands, R., van Scharrenburg, G. J. M., and Wilschut, J. (1998) Mucosal immunoadjuvant activity of recombinant Escherichia coli heat-labile enterotoxin and its B subunit: Induction of systemic $\lg G$ and secretory $\lg A$ responses in mice by intranasal immunization with influenza virus surface antigen. Vaccine. 16: 2069-2076

Yamamoto, S., Kiyono, H., Yamamoto, M., Imaoka, K., Yamamoto, M., Fujihashi, K., Van Ginkel, F. W., Noda, M., Takeda, Y., and McGhee, J. R. (1997) A nontoxic mutant of cholera toxin elicits Th2-type responses for enhanced mucosal immunity. Proc. Natl. Acad. Sci. USA. 94: 5267-5272

Yamamoto, S., Takeda, Y., Yamamoto, M., Kurazono, H., Imaoka, K., Yamamoto, M., Fujihashi, K., Noda, M., Kiyono, H., and McGhee, J. R. (1997) Mutants in the ADPribosyltransferase cleft of cholera toxin lack diarrheagenicity but retain adjuvanticity. J. Exp. Med. 185: 1203-1210 